\title{
Coleoptera from the late Pleistocene forest refugium of the West Siberian Plain
}

\author{
A.A. Gurina*, R.Yu. Dudko*, A.A. Legalov*, E.V. Zinovyev** \\ *Institute of Systematics and Ecology of Animals SB RAS \\ **Institute of Plant and Animal Ecology UrB RAS
}

Slide 2. Open unforested landscapes were predominated in the late Pleistocene (MIS 3 and MIS 2) of West Siberian Plain. This is shown in particular by the entomological data. Insect late Pleistocene assemblages from the north (70$\left.60^{\circ} \mathrm{N}\right)$ were considered as the arctic type, and from the south $\left(57-51^{\circ} \mathrm{N}\right)$ were assigned as non-analogous periglacial type or so called "Otiorhynchus-type fauna" (Legalov et al., 2016; Gurina et al., 2019). Forests are not typical for this time, and insects associated with arboreal vegetation were found in the late Pleistocene deposits sporadically.

Slide 3. Suzun-1 and Suzun-2 sites are somewhat specific and differ from typical periglacial fauna of the region because of Quaternary deposit insect assemblages include forest species. Both are located in the Suzun River valley, right tributary of upper Ob River (Novosibirskaya Oblast, Russia).

The vertical sections Suzun-1 and Suzun-2 are schematic shown on the slide 4. Five samples with insect remains were collected in the layer of blue-gray clay (1.35-0.4 m above water level) of the section Suzun-1. And four another insect samples were taken in the layer of blue-gray sandy-loam (3.2-1.8 m above water level) of the section Suzun-2. Obtained radiocarbon dates are in the slide. Calibrated dates 24893-25966 cal yr BP for Suzun-1 correspond to the end of MIS 3, and 20379-20699 cal yr BP for Suzun-2 correspond to the beginning of MIS 2.

Slide 5. Insect assemblages Suzun-1 and Suzun-2 as well as different samples are very similar to each other. Coleoptera predominated in all samples and represented by al least 19 families and more than 100 species. Curculionidae predominated in the Suzun-1 (39\% of fragments) and Carabidae accounted $20 \%$. The same two families predominated in the Suzun-2 assemblage and represented there almost equally, about $30 \%$ each. Staphylinidae, Tenebrionidae, Chrysomelidae, Silphidae, and Scarabaeidae are also quite abundant in the both sites.

Slide 6. Ecological composition of the assemblages is diverse. There found species which are habitat presently in biotopes of different latitude zones. Tundra, 
boreal forest, and steppe species were found in several samples, as well as different intrazonal species (aquatic, riparian and saline shores).

Slide 7. Species of steppe complex are the most numerous. They represent in the all samples and belong to various families, such as Curculionidae, Carabidae, Tenebrionidae, Byrrhidae, Meloidae, Cerambycidae, Silphidae. Present range of some steppe species includes the studied region, south of West Siberian Plain, such as Harpalus salinus, Cymindis binotata, Porcinolus murinus etc. Another species range far from the Suzun site to south or east. For example, Cymindis kasakh is local endemic of the West Kazakhstan, Scytosoma pygmaeum known from Mongolia and adjacent regions of South Siberia.

Slide 8. Species of tundra complex represent by a few fragments both from Suzun-1 and Suzun-2. They are typical for wet tundra, but some of them known from the northern taiga zone also. Anyway their present day ranges are hundreds kilometers to the north. Association of steppe and tundra complexes is typical for late Pleistocene deposits of the south of West Siberian Plain, and shows to cold and dry conditions of periglacial landscapes in the region.

Slide 9. Forest complex represent by several species only, but it is a peculiarity of the Suzun sites, because of no forest species found in the most of late Pleisocene deposits of the region. The bark beetle Phloetribus spinulosus associated with Picea spp. was identified in the deposits of both sites, at that it was quite numerous in the all samples of Suzun-1 site. Another species of the complex are less specific, but more common in boreal forests. Thus fir forest was probably distributed their in river valleys.

Slide 10. Aquatic complex is quite numerous, it includes about 15 species from the families Dytiscidae, Helophoridae, Hydraenidae and Hydrophilidae, though most species represent by single fragments.

Slide 11. Riparian complex includes a lot species habitat in different biotopes. Some species from this and previous complexes are cold adopted and range in northern regions (such as Bebmbidion difficile), but other are typical for the south (B. almum).

Slide 12. Saline complex represent by several species, but they are found in the all samples of Suzun-1 and Suzun-2 assemblages. All saline species are absent in modern local fauna of Suzun and their presence in the deposits allow to reconstruct conditions drier than now. 
Slide 13. The presence of bark beetle Phloetribus spinulosus associated with Picea, and some other forest species allows to reconstruct fir forest at river valleys. However the proportion of steppe and forest species of Coleoptera in the Suzun assemblages shows the forests probably occupied restricted area only, and opened periglacial steppe landscapes predominated in the region. The high similarity of Suzun-1 and Suzun-2 insect assemblages confirms a gradual MIS3 - MIS2 transition in the region, and indicates the forest refugium existed here quite long time, at least a few thousand years.

The study was partially supported by the Russian Foundation for Basic Research (project no.19-04-00963-a) and the Federal Fundamental Scientific Research Program for 2013-2020 (project no. AAAA-A16-116121410121-7). 